\title{
La postura antiluliana del P. Feijoo
}

\author{
por JOAquin CARRERAS ARTAU \\ Catedrático jubilado de la Universidad de Barcelona
}

Me he ocupado, hace bastantes años, de las polémicas suscitadas en torno a la figura y a las doctrinas de Raimundo Lulio (Ramón Llull) por el P. Feijoo. ${ }^{1}$ Reconstituí, en aquella ocasión, la historia de dichas polémicas; y examiné, por su orden cronológico, la intervención de los varios personajes de todo orden y calidad que contribuyeron a animarlas. No sería decoroso que repitiese en la ocasión presente lo que dije y escrito queda en las Actas de dicho Congreso; pero no podré eludir, como es natural, la aportación de unos cuantos datos fundamentales e imprescindibles para mi nuevo estudio de hoy. Estaba entonces redactando, en colaboración con mi hermano Tomás (q. g. h.), los capítulos sobre historia del lulismo - y, por contraste también, los del antilulismo- de nuestra Historia de la Filosofía Española Cristiana de los siglos $X I I I$ al $X V ;^{2} \mathrm{y}$, ante la invitación de la Asociación Española para el Progreso de las Ciencias, decidimos ambos enviar al Congreso de San-

1. Tomás y Joaquín Carreras y Artau, Feijoo y polémicas lutianas en el siglo XVIJI. Asociación Española para el Progreso de las Ciencias. XIV Congreso, Santiago de Compostela, 1934.

2. Editada por la Asociación Española para el Progreso de las Ciencias, Madrid, tomo I, 1939; tomo II, 1943. Véanse especialmente las págs. 371-376 del tomo II. 
tiago de Compostela en forma de comunicación el trabajo al que antes aludí. Yo compuse la primera parte acerca del P. Feijoo; mi hermano se encargó de la segunda, con su magnífico estudio sobre el P. Pasqual.

Abrigo hoy un propósito bien distinto. Trascendiendo la corteza de los hechos ocurridos, y en aquella sazón reseñados, intentaré mostrar las razones profundas que determinaron la postura antiluliana del Padre Feijoo y pueden servirle, en cierto modo, de justificación. ¡ Y quién sabe si este alegato podrá servir a la vez para justificación mía! Como luliano notorio que soy, he sido tachado de antifeijoniano. ${ }^{3}$ La presente comunicación puede contribuir a precisar el sentido de ambos epítetos, que me han sido más o menos gratuitamente adjudicados.

\section{Feijoo, antiluliano}

EI antilulismo de Feijoo fue una realidad indiscutible, demostrada por los cuatro escritos publicados por él desde el 4 de septiembre de 1726, en que apareció el primer volumen de su Teatro Crítico Universal, hasta el 2 de julio de 1750, en que apareció el volumen tercero de sus Cartas eruditas y curiosas.

El primer escrito es una disertación breve Sobre la arte de Raymundo Lulio, que contiene algunos juicios desfavorables sobre la misma. El P. Colombás cree que esta carta sirvió de respuesta a una consulta que le fue formulada por algún amigo. ${ }^{4}$ Los otros tres escritos son de controversia. En el volumen segundo de las Cartas, publicado en 20 de julio de 1745, insistía en el escrito anterior a pretexto de refutar las alegaciones de sus contradictores PP. Marcos Tronchón y Rafael Torreblanca. En 23 de septiembre de 1749, Feijoo dio a la estampa su Justa repulsa de inicuas acusaciones, con la que contestaba al conocido escritor P. Francisco de Soto y Marne. Y en 2 de agosto de 1750 aparecía, pese a la prohibición real para protección a Feijoo, por iniciativa de éste la Carta erudita respuesta al Rmo. P. Mro. F. Raymundo Pasqual en asunto de

3. García M. Colombás Llull, M. B., «Feijoo y el Lulismo», en Estudios Lulianos, núms. 20-21, Palma de Mallorca, VII, 1963, págs. 1-18 (113-130).

4. Art. cit., pág. 4, texto, y nota 15. 
FEIJOO, ANTILULiANO

la doctrina de Raymundo Lulio, que pone realmente fin a la polémica. Esta había durado, pues, cerca de ocho años; pero terminó con un resultado feliz, pues Feijoo y el P. Pasqual acabaron por entablar buena amistad, reforzada al parecer en trato personal con motivo de haber coincidido ambos en Madrid durante un viaje.

\section{Alcance del antilulismo de Feijoo}

Conviene, ante todo, precisar el alcance de la animadversión de Feijoo contra el arte luliana, pues el matiz aporta ya una primera justificación. Aquélla se concreta al Arte Magna, con exclusión de la persona de su autor. He aquí sus mismas palabras. ‘Déxole y siempre he dexado a salvo a Lulio su santidad, su martyrio y su culto ».5

El parecer de Feijoo se ciñe, pues, a lo doctrinal. Todavía en este terreno importa distinguir entre el Arte y el sistema. El sisteina luliano es un conjunto de doctrinas filosófico-teológicas relativas a Dios, al mundo y al hombre. Lulio las ofrece de ordinario encuadradas en los artificios del Arte Magna, en términos que para el lector común resulta sumamente difícil el deslinde entre uno y otro. Pero en algunos raros casos, para eludir las críticas de sus coetáneos contra el Arte, Lulio ha prescindido de él y ha presentado sus doctrinas en forma llana y sencilla. Así lo ha hecho, por ejemplo, en su gran enciclopedia Arbol de la Ciencia, ${ }^{6}$ expresión máxima del sistema sin el Arte. A la perspicacia de Feijoo no le escapó la distinción, por más que no la formulara en términos explícitos. Y, aún sabiendo que las doctrinas de Ramón Llull no gozaban de general aceptación, antes bien algunas de ellas eran tachadas de temerarias y heterodoxas por escolásticos de otras tendencias, en especial por los teólogos dominicos, en un alarde de ecuanimidad Feijoo prescinde de estas rencillas de escuela y, pese a sus censuras contra el Arte Magna, escribe: "No obsta a que el autor merezca aplausos por otros capítulos.» En otros pasajes es todavía más explícito en los elogios que tributa a las doctrinas lulianas.

5. Feijoo, Sobre la arte de Raymundo Lulio, n.o 77.

6. Véase la edición reciente de esta obra en su texto catalán, con anotaciones mías, en Obres Essencials de Ramón Llull, Tomo I, Barcelona, 1957. 
Resulta, pues, que la enemiga de Feijoo contra Llull se limita puramente al Arte. Y ¿qué es el Arte Magna? En otro lugar ${ }^{7}$ he esquematizado el artificio luliano en tres elementos integrantes: a) un reducido número de conceptos básicos, a saber, las «dignidades» divinas; b) una combinatoria para el enlace y desarrollo de tales conceptos; y c) un sistema de símbolos, matemáticos y alfabéticos principalmente, para la exacta expresión de las verdades resultantes. Como era habitual en la Edad Media, Llull atribuye a inspiración divina la idea germinal de su Arte y tiene en ella una fe tan ciega que cree poder demostrar las verdades de su sistema, sobre todo al polemizar con los musulmanes y con los infieles en general, para cuya conversión - es decir, con finalidades claramente apologéticas - el Arte había sido planeado y puesto en práctica por su autor.

Pues bien: es contra la enseñanza y perpetuación de este artificio que insurge la crítica de Feijoo. A su juicio, esta Arte es inútil y hace perder el tiempo a quienes se empeñan en aprenderla, sorteando las considerables dificultades que le son inherentes. He aquí las propias palabras de Feijoo:

«Digo que si los que se dedican a aprehender el Arte de Lulio, empleassen el tiempo que gastan en ello en leer otros libros buenos, se hallarían al fin de la quenta con muchas útiles noticias, quando de Lulio no pueden sacar conocimiento alguno, sí sólo explicar (mejor diría implicar) con una misteriosa jerigonza lo que ya saben por otro estudio. Esta compassión me movió a la obra de misericordia de desengañar a los pobres que caen, o en adelante pueden caer, en error tan nocivo, para que no malogren miserablemente el tiempo...8

Queda, pues, perfectamente precisado el alcance del antilulismo de Feijoo: considera inútil el Arte luliana; en consecuencia, desaconseja su estudio para ahorrar pérdida de tiempo. En su lugar, aconseja seguir el camino tradicional, que conduce a la trabajosa adquisición de la ciencia; y éste no es otro que aprender la lógica y la metafísica de Aristóteles.

7. J. Carreras Artau et J. Tusquets Tarrats, Apports hispaniques à la plitosophie chrétienne de Occident. Chaire Mercier, Louvain, 1961 (véase la $2, a$ conferencia).

8. Feijoo, Justa repulsa de iniquas acusaciones, Madrid, 1757; p. 8-9. 


\section{Ambientación histórica}

Se engañaría quien atribuyese la postura antiluliana de Feijoo a simples querellas internas de escuela, en las que es tan pródigo nuestro siglo XVIII. En ese pecado incurrieron, más bien, sus contradictores, si exceptuamos al P. Pasqual. En cambio, el antilulismo de Feijoo refleja el desencanto y aún el descrédito que cundía a la sazón en Europa respecto al Arte Magna de Ramón Llull.

El auge portentoso de esa Arte tuvo lugar en el Renacimiento. Al generalizarse las críticas contra el Organon de Aristóteles, al que se acusaba de ser un método meramente demostrativo de las verdades ya sabidas, empezó la búsqueda de un método inventivo. Los partidarios del Arte Magna encontraron en esos siglos el terreno abonado para la divulgación de esa pretendida panacea universal del saber, pues no sólo la presentaban como un método inventivo, sino además aplicable a todas las ciencias, es decir, conducente a la constitución de la enciclopedia, que ha sido el ideal buscado con afán en la época.

El fracaso de la empresa por todos cuantos la intentaron, y sobre todo la constitución de la nueva ciencia y de la nueva filosofía a partir de la divulgación de las ideas de Francisco Bacon y de Renato Descartes, provocaron de rechazo el descrédito del Arte luliana. Téngase en cuenta que uno y otro, considerados ambos como padres de la filosofía moderna, empezaron por resolver el problema del método. ${ }^{9}$

\section{Los motivos del antilulismo de Feijoo}

A Feijoo le asistía más de un motivo para enfrentarse con el Arte Magna de Lulio. Ante todo, su acendrado aristotelismo, como titular durante largos años de Lógica y Metafísica de Aristóteles en esta Universidad de Oviedo. La rivalidad entre aristotélicos y lulianos era ya tradicional. No en vano, el Arte Magna de Lulio fue el único sistema de

9. Sobre la marcha de este proceso íaeológico en Europa, véanse los capítulos pertinentes de nuestra Historia..., citada en la nota 2. 
Lógica que a lo largo de toda la Edad Media pretendió invalidar el método aristotélico. Aún dejando de lado los interminables ataques de los dominicos, seguidores del inquisidor Nicolás Eymerich, un pensador tan ponderado como Pedro Ciruelo de Daroca había sometido en pleno Renacimiento a una crítica inteligente, pero implacable, el Arte Iuliana, combatiendo sobre todo en nombre del aristotelismo las pretensiones lulianas de constituir un arte universal para todas las ciencias. Feijoo adopta, dos siglos después, una postura semejante.

Pero el factor principalísimo que inspiró a Feijoo sus críticas sobre el Arte luliana, fue su europeísmo. El sabio benedictino, tan familiarizado con la literatura europea de la época, había leído, sin duda, los juicios de Descartes desfavorables a Llull en el Discurso del Método, los del canciller inglés Francisco Bacon a quien cita expresamente y los de otros escritores, franceses sobre todo, cuyos nombres sonaron a lo largo de la polémica; y harto le constaba al buen monje que el ambiente europeo estaba cambiando rápidamente en sentido desfavorable al Arte luliana. Como de tantas otras ideas y tendencias europeas, Feijoo se hace también eco de ésta en España. Una vez más, Feijoo se ha mostrado a la altura de su europeísmo.

Este aserto urge, sin embargo, una distinción. Solamente en una parte de Europa el Arte luliana entró rápidamente en decadencia, a saber, en los países anglosajones y en Francia y demás países latinos, en los cuales prendió el empirismo. El Arte Magna se halla en los antípodas del nuevo método triunfante. Esto solo bastaría para explicar el desvío del P. Feijoo hacia la misma; pues es bien sabido que él es uno de los principales introductores del empirismo en España, sobre todo en el campo de las ciencias, y muy en especial de la medicina.

Contrariamente ocurría en Alemania y en los demás países del Este de Europa, dominados por la corriente racionalista. Allí todavía era posible que un gran filósofo como Guillermo Leibniz soñara en transformar el Arte Magna de Lulio en una verdadera Enciclopedia constituida a partir del "alfabeto de los conocimientos humanos» y desarrollada apriorísticamente en forma de una combinatoria matemática, claro precedente de la Lógica matemática de nuestros días. Un discípulo de Leibniz, Ivo Salzinger, proyectó y realizó en su parte más sustancial la edición de las obras de Raimundo Lulio, la llamada «edición maguntina», bajo la protección y el mecenazgo del Gran Elector de Maguncia. La extensa cultura de Feijoo no alcanzaba probablemente a estas manifestaciones de la cultura europea. Pero sus contradictores mallorquines no las ignoraban; el P. Fornés y el P. Pasqual habían colaborado intensa- 
FEIJOO, ANTILULIANO

mente en los trabajos europeos de Ivo Salzinger. La actitud de los contradictores de Feijoo no deja de tener su parte de razón.

\section{Consecuencia de la actitud del P. Feijoo}

Los historiadores no acostumbran a seguir el rastro de la polémica entre Feijoo y los lulianos más allá de la correspondencia y el encuentro personal suyos con el P. Pasqual en Madrid. Con lo cual dan la impresión de haber terminado la polémica en una especie de «abrazo de Vergara». Nada más falso.

La postura antiluliana del P. Feijoo tuvo incalculables consecuencias; señalaré dos o tres de ellas. Desde luego, el impacto enorme en la opinión pública; pues los artículos de Feijoo equivalían en la época a verdaderas campañas periodísticas. Indudablemente, las publicaciones del benedictino gallego son un precedente de la prensa de nuestros días.

Pero señalaré efectos más concretos. Cuando Feijoo replicaba a sus adversarios que el Arte Magna de Lulio había dejado de enseñarse en todas las Universidades de Europa, menos en las de España por razones de patriotismo, todavía existían cátedras lulianas en las Universidades de Salamanca, de Valencia y de Mallorca. El ataque de Feijoo infirió una herida de muerte al lulismo doctrinal. Las enseñanzas lulianas en Salamanca y en Valencia, que desempeñaban respectivamente los PP. Fornés y Luis de Flandes - dos adversarios de Feijoo en la polémica- no fueron continuadas, que yo sepa. En cuanto a su más valioso contrincante, el P. Raymundo Pasqual, ha sido el último gran representante del lulismo doctrinal en Mallorca. Por razones de patriotismo local subsistieron en esa isla las cátedras de filosofía luliana hasta la supresión de la Universidad Luliana.

Bien es verdad que a comienzos del presente siglo se produjo un intento de reviviscencia del lulismo como sistema vivo filosófico, escolástico, a cargo del Obispo Maura, del Rdo. D. Salvador Bové y del Dr. Sureda Blanes, fundador de la actual Escuela Luliana de Mallorca. Con su desaparición podemos considerar liquidado el lulismo doctrinal.

Una consecuencia inesperada de las campañas antilulianas del Padre Feijoo fue la decisión pontificia adoptada por el Papa Benedicto XIV en 
3 de marzo de 1753: Revideantur opera Lulli. Desde un par de siglos, por lo menos, estaba incoada en Roma una causa de canonización de Raimundo Lulio que en la Curia romana tropezaba con una fuerte oposición, alimentada por los adversarios, quienes pretendían la condenación formal de sus obras. Mientras reinaron en España los Austrias, la diplomacia real contuvo el movimiento antiluliano. Pero, al subir al poder los Borbones, se desentendieron de la causa luliana; y el movimiento contra Lulio ganó prosélitos en Roma. Los escritos antilulianos de Feijoo fueron la gota de agua que hizo derramar el vaso. En el documento pontificio, ligeramente posterior al último escrito antiluliano del sabio benedictino, la autoridad de éste es alegada como antecedente inmediato de la resolución. ${ }^{10}$

\section{Epílogo}

Con las Disertaciones históricas del jesuita P. Custurer (1700) y las Vindiciae lullianae del P. Pasqual comienza un nuevo lulismo, al que podemos calificar de erudito. Esta corriente ha ido asimilando, cada vez más, los métodos críticos de la investigación histórica hasta hallar su adecuado encaje en la moderna Historia de la Filosofía Medieval. Precisamente estamos hoy asistiendo a un florecimiento esplendoroso de los estudios lulianos en Europa, cuya reseña estaría aquí fuera de lugar. Personalmente, soy un entusiasta de este movimiento. Nunca me han preocupado los «ismos» ni los «anti»; ni me importa demasiado que me tachen de Iulista o de antifeijoniano. Mi única pasión es la historia, imparcial y objetiva, del pensamiento español.

10. J. Tarré, «Un document del Papa Benet XIV sobre el lullisme", en Estudis Universitaris Catalans, XX, 1935, págs. 158-159. 